\title{
Mitotic delay dependent survival identifies components of cell cycle control in the Drosophila blastoderm
}

\author{
Douglas M. Ruden* and Herbert Jäckle \\ Max-Planck-Institut für biophysikalische Chemie, Abteilung Molekulare Entwicklungsbiologie, Am Fassberg, D-37077 Göttingen, \\ Germany
}

*Author for correspondence at present address: Department of Physiology and Cell Biology, The University of Kansas, Lawrence, Kansas 66045, USA

\section{SUMMARY}

The Drosophila body pattern is laid down by maternal and zygotic factors which act during the early phase of embryonic development. During this period, nascent zygotic transcripts longer than about 6 kilobases are aborted between the rapid mitotic cycles. Resurrector ${ }^{1}$ $\left(\operatorname{Res}^{1}\right)$ and $\operatorname{Godzilla}^{1}\left(\operatorname{God}^{1}\right)$, two newly identified dominant zygotic suppressor mutations, and a heterozygous maternal deficiency of the cyclin $B$ locus, complement the partial loss of function of the segmentation gene knirps (kni) by extending the length of mitotic cycles at blastoderm. The mitotic delay caused by $\operatorname{Res}^{1}$ and $\operatorname{God}^{1}$ zygotically and by the deficiency of the cyclin $B$ locus maternally allows the expression of a much longer transcript of a kni cognate gene normally aborted between the short mitotic cycles and consequently allows survival of kni mutant progeny. In addition to the practical benefits of identifying mutations in Drosophila cell cycle regulatory genes as suppressors of $k n i$, our results have evolutionary implications regarding the flexibility of the genome to meet sudden selective pressures by recruiting cognate genes to function.

Key words: Drosophila, cyclin A mutant, cyclin B mutant, Resurrector mutant, Godzilla mutant, blastoderm mitotic cycle

\section{INTRODUCTION}

Drosophila segmentation is regulated by a cascade of sequentially acting factors, which divide the embryo into smaller units. The maternal coordinate genes such as bicoid (bcd) and nanos (nos) initially organize the embryo into anterior and posterior portions (St Johnston and Nüsslein-Volhard, 1992). The maternal genes in turn regulate transcription of the zygotic gap genes such as hunchback (hb), Krüppel (Kr), knirps (kni), and tailless ( $t l l$ ) which subdivide the embryo into broad regions along the anterior-posterior axis (Pankratz and Jäckle, 1993). The gap gene kni is initially expressed during mitotic cycle 12 in the region corresponding to the abdominal segment primordium (Nauber et al., 1988). An allelic series for $k n i$ includes a null allele $\left(k n i^{F C 13}\right)$, which is missing in six out of the eight abdominal segments, an intermediate allele $\left(k n i^{14 F}\right)$, which is missing three or four abdominal segments (Lehmann, $1985)$, and the weakest allele $\left(k n i^{P 5}\right)$, which is missing one or two abdominal segments (this work).

The gap genes are initially expressed during the syncytial mitotic cycles, which are about 10 minutes long. Shermoen and O'Farrell (1991) have shown that transcription of genes is aborted between embryonic mitotic cycles. Since the rate of transcription is approximately $1.4 \mathrm{~kb} /$ minute, genes longer than about $6 \mathrm{~kb}$ will therefore be aborted between the short mitotic cycles when the gap genes are expressed (Shermoen and O'Farrell, 1991; Thummel et al., 1990). This suggests that coordination between mitotic cycle length and gene size rep- resents a severe physiological barrier for gene function (Gubb, 1986; O'Farrell, 1992). The theoretical limitation of gene length on activity during these early mitotic cycles has been confirmed for the kni cognate gene knirps-related $(k n r l)$, which differs from kni mainly by having $19.1 \mathrm{~kb}$ instead of $0.9 \mathrm{~kb}$ intron sequences (Rothe et al., 1989, 1992, 1994). Even though the expression patterns and biochemical functions of kni and $k n r l$ are apparently identical, $k n r l$ does not function in abdominal segmentation because its large primary transcript cannot be fully transcribed when its activity would be required for the establishment of abdominal segments (Rothe et al., 1992). However, $k n r l$ can provide weak kni-like segmentation function in the embryo when expressed from a transgene construct that is based on an intron-less knrl cDNA (Rothe et al., 1992).

To understand the control of kni both in terms of transcription regulatory mechanisms and spatial-temporal regulatory mechanisms, it is crucial to elucidate the factors involved in these regulatory processes. We took a genetic approach to identify new factors involved in the regulation of kni. As had been found in similar genetic screens in yeast, we expected that gain-of-function mutations in genes involved in either upstream regulation of kni or in basic components of the transcription regulatory machinery would be isolated as zygotic suppressors of a hypomorphic allele of a transcription factor such as kni (Himmelfarb et al., 1990; Berger et al., 1992; Swaffield et al., 1992). However, the two zygotic suppressors of kni we isolated in the work presented here, Resurrector ${ }^{1}$ 
$\left(\operatorname{Res}^{l}\right)$ and Godzillal $\left(\operatorname{God}^{l}\right)$, appear to be, or to interact with, cell cycle regulatory components. Genetic and cell biological characterization of these two zygotic suppressors suggest that they are involved in sister chromosome segregation during the blastoderm stage and function as kni suppressors by causing mitotic cycle delays at metaphase stages during blastoderm. These mitotic cycle delays result in precocious expression of the knrl gene, which compensates for the partial loss of kni activity, allowing kni mutant progeny to survive. Consistent with this hypothesis, we show that females heterozygous for a deficiency of cyclin B (Knoblich and Lehner, 1993) will enable kni mutant progeny to survive, presumably also through a blastoderm mitotic cycle delay as has been published earlier (Edgar et al., 1994). The identification of $\operatorname{Res}^{1}$ and $\operatorname{God}^{1}$ as dominant zygotic kni suppressors and a deficiency of the cyclin $B$ locus as a dominant maternal kni suppressor demonstrates that both zygotic and maternal mutants of the cell cycle machinery, which interfere with gene activities at specific stages during development, can be isolated in this approach. Finally, we discuss how this work reveals a novel evolutionary mechanism in which a single mutational event can allow a cognate gene to function, thus providing greater flexibility to adapt to selective pressures.

\section{MATERIALS AND METHODS}

\section{Fly strains}

The fly strains containing the mutations in $\operatorname{cyclin} A\left(c y c A^{5}\right)$ and the deficiency of the cyclin $B$ locus $(\operatorname{Df}(2 \mathrm{R}) 59 \mathrm{~A}, \mathrm{~B})$ were from Christian Lehner (Knoblich and Lehner, 1993). All other fly stocks were from the Bloomington, Bowling Green, or Tübingen stock collections. Wild-type flies were Oregon R.

\section{Screen for kni $^{14 F}$ suppressors}

In the two genetic screens for suppressors of $k n i^{14 F}$, a total of 4,000 ethylmethane sulfonate (EMS; $30 \mathrm{mM}$ ) (Ashburner, 1989) mutagenized males of genotype st $k n i^{14 F} p^{p} / \mathrm{TM} 3, S b$ (for markers and balancers, see Lindsley and Zimm, 1992) were crossed to 8,000 nonmutagenized virgins of genotype $s t k n i^{F C l 3} \mathrm{Ki} \mathrm{p}^{p}$ e / TM3,Sb. The males were removed after 3 days and females were transferred daily (total of 8 days). Of the approximately $200,000 \mathrm{~F}_{1}$ adult progeny, 87 flies (60 females and 27 males) had the apparent genotype st kni ${ }^{14 F}$ $p^{p} / s t k n i^{F C l 3} \mathrm{Ki} p^{p} e$. Only two adults, one from each screen and both males, were fertile and continued to produce apparent kni-mutant homozygous progeny when mated to st $k n i^{F C l 3} \mathrm{Ki} \mathrm{p}^{p}$ e / TM3,Sb virgins. Genetic analysis of these $k n i^{14 F}$ suppressors indicates that the suppressor isolated in the first screen, termed $\operatorname{Res}^{1}$, maps to a single locus on the third chromosome within 2 centimorgans of $c a$ (D. M. $\mathrm{R}$., unpublished data). Since $k n i^{14 F}$ is a $245 \mathrm{bp}$ deletion and $k n i^{F C 13}$ is a $2 \mathrm{~kb}$ deficiency (see Fig. 4; Gerwin et al., 1994), the survival of

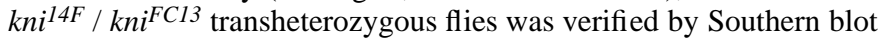
analysis of adult flies (data not shown; Sambrook et al., 1989).

The suppressor isolated in the second screen for dominant zygotic suppressors, termed $\operatorname{God}^{l}$, is associated with a chromosomal translocation and involves at least two loci (Fig. 3A). When the recessive lethal mutation $k n i^{14 F}$ and a background recessive lethal mutation located at 38B, termed Mothra ${ }^{l}\left(\mathrm{Mot}^{l}\right)$, are removed by genetic recombination from the translocation chromosomes, the God $^{l}$ translocation is homozygous viable. The cleaned up God $^{I}$ translocation chromosome showed a recessive maternal bicaudal-like phenotype (Fig. 2B) and a recessive wing-vein patterning defect (Fig. 3B). The cleaned up $\mathrm{God}^{l}$ translocation chromosome was also used to generate the $\operatorname{God}^{1} \mathrm{kni}^{P 5}$ double mutant stock (Table 2). Further genetic analysis revealed that the second chromosome break of the $\operatorname{God}^{l}$ translocation is not viable over $\mathrm{Df}(2 \mathrm{R}) \mathrm{Px} 2(60 \mathrm{C} 5-6$; 60D9-10), $\mathrm{Df}(2 \mathrm{R}) \mathrm{Px} 4(60 \mathrm{~B} 1$ D1), nor the recessive lethal C606 (Kimble et al., 1990) and did not complement the recessive wing vein patterning mutations blistered (bs) and balloon (ba) (Lindsley and Zimm, 1992).

\section{Screen for $\boldsymbol{R e s}^{\mathbf{1}}$ revertants}

Revertants of $\operatorname{Res}^{1}$ were isolated in an $\mathrm{F}_{2}$ screen for $k n i^{14 F}$ Res $^{1}$ flies that are no longer able to produce kni transheterozygous mutant progeny. 5,000 st kni $^{14 F} p^{p}$ Res $^{1}$ / TM3,Sb males were mutagenized as described above and mated to 10,000 st kni ${ }^{F C 13} \mathrm{Ki} p^{p} e / \mathrm{TM} 3, \mathrm{Sb}$ virgins. 10,000 (st kni $\left.{ }^{14 F} p^{p} \operatorname{Res}^{1}\right)^{*} / \mathrm{TM} 3, S b \mathrm{~F}_{1}$ males were then individually mated to $s t k n i^{F C 13} K i p^{p}$ e / TM3,Sb virgins in separate vials. Three vials did not produce any $\left(s t k n i^{14 F} p^{p} \operatorname{Res}^{I}\right)^{*} /$ st kni ${ }^{F C l 3} \mathrm{Ki} \mathrm{p}^{p}$ $e$ F2 progeny and these three potential $\operatorname{Res}^{l}$ revertants were balanced and labeled $\operatorname{Res}^{1 r 1}$, Res ${ }^{1 r 2}, \operatorname{Res}^{1 r 3}$. Res ${ }^{1 r 1}$ is not null for $\operatorname{Res}^{1}$ but still has partial suppressor function whereas $\operatorname{Res}^{1 r 2}$ and $\operatorname{Res}^{1 r 3}$ appear to be null mutations and have no residual suppressing activity (data not shown). Because $\operatorname{Res}^{1 r l}$ still shows some suppressing activity and, unlike $\operatorname{Res}^{l}$, is not a partially penetrant dominant female-sterile mutation, the $\operatorname{Res}^{1 r l}$ derivative was used to position the suppressor, by genetic recombination, onto the ru h th cu sr e ca multiple-marker third chromosome and subsequently onto the $k n i^{F C l 3}$ and $\mathrm{Df}(3 \mathrm{~L}) r i^{X T 1}$ chromosomes (see embryos in Fig. 1F and 1G). Since Res ${ }^{1 r 1}$ can be recombined with different $k n i$ alleles and still suppress the $k n i$ abdominal phenotype, the suppressor and kni are separable genetic functions.

\section{Isolating the $\boldsymbol{k n i}^{\mathrm{P5}}$ mutation}

The hypomorphic P-allele of $k n i, k n i^{P 5}$, was isolated in an $\mathrm{F}_{2}$ screen using a stock containing the Birmingham second chromosome with transposase-minus P-elements, Birm-2 and a stock that provides Ptransposase constitutively P[ry+ 2-3](99B) (Robertson et al., 1988; Ballinger and Benzer, 1989). Birm-2; st Ki $p^{p}$ e / TM3,Sb males were mated to $S b$ P[ry+ 2-3](99B) / TM6B, $H u D r$ females. 1,000 Birm-2 I +: st Ki $p^{p}$ e / Sb P[ry+ 2-3](99B) 'jumper males' were then mass mated to 2,000 st kni ${ }^{F C 13} p^{p} / \mathrm{TM} 3, S b$ virgins and 5,000 (st Ki p p e $)^{*}$ / TM3,Sb F1 males were mated to Df(3R)ri ${ }^{X T 1}$, ru st e ca / TM3,Sb virgins in individual vials. Three vials did not produce any $\left(s t\right.$ Ki $p^{p}$ $e)^{*} / \mathrm{Df}(3 \mathrm{R}) r i^{X T 1}$, ru st e ca progeny. The P-insertion mutagenized third chromosomes were balanced over TM3 and one chromosome, $k n i^{P 5}$, had a P-element located at the kni locus. PCR amplification followed by sequencing analysis revealed that the P-element is flanked by an 8 bp post-insertionally duplicated sequence $\left(5^{\prime}\right.$ GGTGGTGG P-element GGTGGTGG 3'), which is located $155 \mathrm{bp}$ before the startpoint of transcription of the kni gene (Nauber et al., 1988; data not shown). The stock containing $k n i^{P 5}$ reverts to wild type at a high frequency when crossed to a stock which contains a constitutive source of P-transposase (Robertson et al., 1988; data not shown).

\section{RNA-PCR analysis}

RNA-PCR analysis (Foley et al., 1993) of individually staged embryos was done as follows. Embryos from a 1 hour egg collection on apple juice-agar plates were dechorionated (Ashburner, 1989). For staging under the microscope, single embryos were placed into the wells of a microtiter plate containing $1 \mu \mathrm{l}$ of $3 \mathrm{~S}$ Votalef oil. The beginning of the 11th mitotic cycle was determined by morphological criteria (Foe and B. Alberts, 1983; Foe, 1989). The two subsequent divisions were determined by direct observation. The end of each division cycle was determined by the disappearance of visible nuclei. Embryos were punctured with a sterile 26 gauge needle after cycle 11,12 , or 13 and after cellularization during cycle 14 . The contents of the embryo $(10 \mathrm{nl})$ was taken up in $10 \mu \mathrm{l}$ of doubledistilled water, transferred into a sterile PCR reaction vessel and immediately frozen in liquid nitrogen. Samples were thawed at room temperature and hybridization cocktail $(15 \mu \mathrm{l} ; 1 \times$ Taq DNA poly- 
merase buffer (Stratagene, San Francisco) supplemented with $0.1 \mathrm{mM}$ dNTPs and $0.1 \mathrm{mM} \mathrm{knrl}$ primers $\mathbf{A}, \mathbf{B}, \mathbf{C}$, and $\mathbf{D}$; see below) was added to each vial. The vials were placed in a $55^{\circ} \mathrm{C}$ water bath $(10$ minutes) and then cooled slowly. When the temperature reached $37^{\circ} \mathrm{C}, 20$ units of MULV-reverse transcriptase (RT; Stratagene, San Francisco) were added $\left(37^{\circ} \mathrm{C} ; 30\right.$ minutes) to generate cDNA. After heat inactivating the RT $\left(100^{\circ} \mathrm{C} ; 10\right.$ minutes $), 20$ units of Taq DNA polymerase (Stratagene, San Francisco) and $10 \mu \mathrm{Ci}[\alpha-32 \mathrm{P}] \mathrm{dCTP}$ were added and PCR was programmed as follows: 5 minutes at $94^{\circ} \mathrm{C}$ followed by 30 cycles $\left(94^{\circ} \mathrm{C}\right.$ for 30 seconds, $55^{\circ} \mathrm{C}$ for 1 minute, and $72^{\circ} \mathrm{C}$ for 1 minute) in a Perkin Elmer PCR machine. The following primers sequences were used: primer A (5' GTCCCACGGAAATATCTCTAGCTA 3'); bp 45-68 in the first knrl exon; primer B (5' TCGTGAATCACCGAGCCCGTGTTG 3'); bp 485-508 in the second $k n r l$ exon; primer C (5' CGGAGCCTTTACATGCGAGGGCTG 3'); bp 598-617 in the third knrl exon; primer D (5' ATGACTGCCATCGGCACCACTTGA 3'); bp 1247-1260 in the forth $k n r l$ exon (Rothe et al., 1989).

\section{RESULTS}

\section{$R^{1}{ }^{1}$, a dominant zygotic suppressor of a $\mathrm{kni}$ hypomorphic phenotype}

In order to understand better the regulation of $k n i$, we undertook a screen for suppressors of this key segmentation gene. The alleles of kni that we used in this analysis were $k n i^{P 5}$, which is a weak allele (this work; see Materials and Methods), $k n i^{14 F}$, which is an intermediate allele, and $k n i^{F C 13}$, which is a null allele (Fig. 1; Lehmann, 1985). To isolate dominant zygotic suppressors of the kni mutation, adult male flies carrying the $k n i^{14 F}$ chromosome were treated with ethylmethane sulfonate (EMS), crossed to virgin females carrying the $k n i^{F C l 3}$ chromosome, and viable $k n i^{14 F} / k n i^{F C l 3}$ progeny were screened as described in Materials and Methods. In the course this screen, which involved over $100,000 \mathrm{~F}_{1}$ progeny, a single dominant suppressor was isolated, termed Resurrector ${ }^{1}$ $\left(\operatorname{Res}^{l}\right)$ (Table 1).

To determine whether $\operatorname{Res}^{1}$ is a hypomorphic or a neomorphic mutation, we screened for revertants of $\operatorname{Res}^{l}$. If a suppressor functions by having a reduced level of a product (see cyclin $B$, below), then one would not expect to be able to obtain revertants of that suppressor. If, on the other hand, a suppressor is a neomorphic mutation that causes the product to function in a novel manner, then one can isolate revertants of the suppressor that knock out the novel function. In a sub- sequent screen for revertants of $\operatorname{Res}^{1}$, three revertants were isolated, termed $\operatorname{Res}^{1 r 1}, \operatorname{Res}^{1 r 2}, \operatorname{Res}^{1 r 3}$. One of these revertants, $\operatorname{Res}^{1 r l}$, partially suppresses the $k n i^{14 F} / k n i^{F C 13}$ segmentation phenotype, but not the lethality associated with the $k n i^{14 F}$ / $k n i^{F C l 3}$ combination. The other two revertants have no suppressing function (see Materials and Methods). This experiment suggests that $\operatorname{Res}^{1}$ is caused by a neomorphic mutation and not a hypomorphic mutation.

Table 1 shows that flies carrying a chromosome that contains both $\operatorname{Res}^{1}$ and $k n i^{14 F}$ efficiently produce $k n i^{14 F} \operatorname{Res}^{1} / k n i^{F C 13}$ progeny, regardless of whether $\operatorname{Res}^{1}$ is provided maternally or paternally. A genetic recombination analysis reveals that $\operatorname{Res}^{1}$ is located within two centimorgans of the $c a$ locus near the telomere of the right arm of chromosome three (99A1), whereas kni is located near the centromere of the left arm of chromosome three $(78 \mathrm{E} 1,2)$. The large genetic distance between kni and $\operatorname{Res}^{l}$ suggests that the suppressor is extragenic and acts in trans to kni (see Materials and Methods). To exclude the possibility that suppression results from the duplication and subsequent transposition of the kni locus to the telomere of 3R, we carried out in situ analysis of polytene chromosomes using kni DNA as a probe. Such experiments revealed only endogenous kni DNA at 78E1,2 (data not shown). $\operatorname{Res}^{l}$, in addition to suppressing kni, has a partially penetrant dominant female sterile phenotype in which a high frequency of embryos from females heterozygous for Res ${ }^{1}$ have a bicaudal-like phenotype in which there is a mirror image duplication of the abdominal segments (Fig. 2A; see Discussion). $k n i^{14 F} \operatorname{Res}^{1} / k^{1} i^{14 F} \operatorname{Res}^{1}$ embryos have a wildtype abdominal segmentation phenotype, a defective head cytoskeleton, and are embryonic lethals (not shown).

Interestingly, $99 \%$ of the progeny inherit $\operatorname{Res}^{1}$ regardless of whether Res ${ }^{1}$ is provided maternally or paternally (Table $1)$, indicating what might be an example of genetic selfishness (Dawkins, 1989; Lyttle, 1993; see Discussion). As with Segregation distorter $(S d)$ mutations that are dependent on a separate Responder (Rsp) locus to observe the chromosome segregation defect, $\operatorname{Res}^{1}$ is dependent on a second locus to observe the chromosome segregation defect. kni ${ }^{14 F} \operatorname{Res}^{1} /$ TM3 parents mated to wild-type flies produce a majority of $k n i^{14 F} \operatorname{Res}^{1} /+$ progeny (Table 1 and data not shown). However, $k n i^{14 F} \operatorname{Res}^{1} / \mathrm{TM} 6, k^{14 F} \operatorname{Res}^{1} / \mathrm{TM} 1$, and $k n i^{14 F}$ $\operatorname{Res}^{1} /$ + parents mated to wild-type flies produce $k n i^{14 F} \operatorname{Res}^{1}$ I + progeny at normal rates (data not shown). This suggests that a $R s p$ sensitive $\left(R s p^{s}\right)$-like locus for $\operatorname{Res}^{1}$ is present on

Table 1. Res $^{1}$ rescues homozygous kni mutant embryos to fertile adults

\begin{tabular}{|c|c|c|c|c|c|}
\hline \multirow[b]{2}{*}{ Genotype of mating pairs* } & \multicolumn{5}{|c|}{$\mathrm{F}_{1}$ genotype ( $\%$ of surviving adults) $\dagger$} \\
\hline & $k_{n i}{ }^{14 F} / k^{2} i^{F C l 3}$ & $k n i^{14 F} / T M 3$ & $k n i^{F C l 3} / T M 3$ & $k_{n i}{ }^{14 F} \operatorname{Res}^{1} / k_{n i}{ }^{F C l 3}$ & $\mathrm{kni}^{14 F} \operatorname{Res}^{1} / T M 3$ \\
\hline 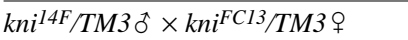 & 0 & $49.1 \pm 8.6$ & $50.9 \pm 8.6$ & - & - \\
\hline $\mathrm{kni}^{14 F} \operatorname{Res}^{\mathrm{l}} / \mathrm{TM} 3$ oे $\times \mathrm{kni}^{\mathrm{FCl}} / \mathrm{TM} 3$ ㅇ & - & - & $0.4 \pm 1.0 \S$ & $75.9 \pm 7.1 \ddagger$ & $21.3 \pm 9.2$ \\
\hline $\mathrm{kni}^{14 F} \operatorname{Res}^{1} / T M 3+\times \mathrm{kni}^{F C 13} / \mathrm{TM} 3$ ठิ & - & - & $0.2 \pm 0.6 \S$ & $62.4 \pm 8.1 \div$ & $35.6 \pm 11.8$ \\
\hline
\end{tabular}

*See Materials and Methods for exact genotypes. A single male (left) was crossed to two virgins (right) at $25^{\circ} \mathrm{C}$ and the parents were removed before the first pupae hatched. No significant difference has been observed in reciprocal crosses or if the crosses are done at $18^{\circ} \mathrm{C}$ (data not shown).

$\dagger$ The $F_{1}$ genotypes, their distribution, and standard deviations are shown from ten sets of flies, which produced $\geq 10 \mathrm{~F}_{1}$ progeny. Total number of scored $F_{1}$ progeny is 1000 (top row) and 192 (second row), and 124 (third row).

$\ddagger \operatorname{Res}^{I}$ allows survival of $k n i$-mutant homozygous adults at a high frequency. These flies are fertile and have been maintained as stocks for more than 10 generations.

§Note that the $k n i^{14 F} \operatorname{Res}^{l}$ chromosome is inherited in approximately $99 \%$ of the progeny at the expense of the TM3 balancer chromosome. This is an apparent example of genetic selfishness (see text). 

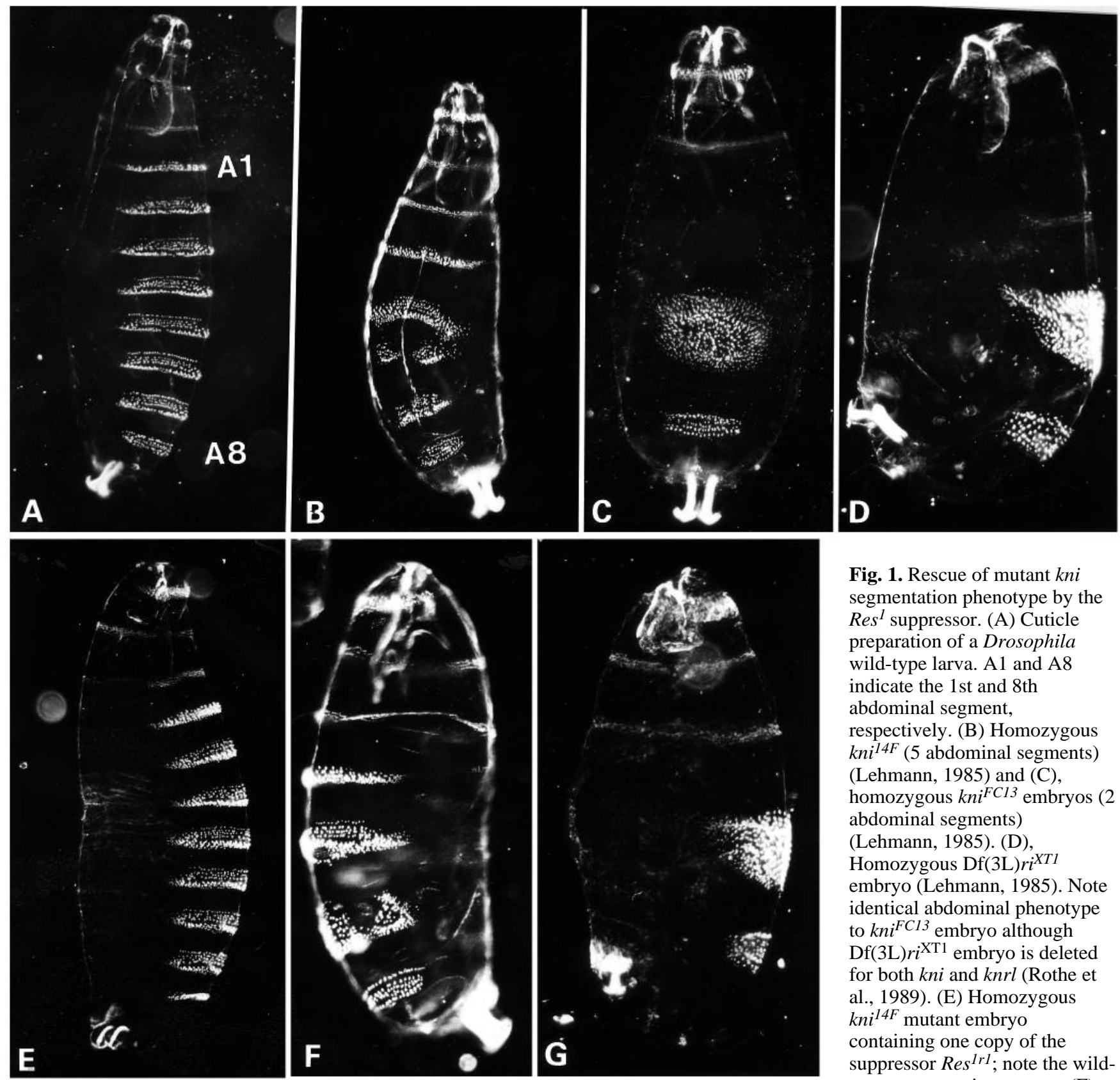

Fig. 1. Rescue of mutant $k n i$ segmentation phenotype by the $\operatorname{Res}^{1}$ suppressor. (A) Cuticle preparation of a Drosophila wild-type larva. A1 and A8 indicate the 1st and 8th abdominal segment, respectively. (B) Homozygous $k n i^{14 F}$ (5 abdominal segments) (Lehmann, 1985) and (C), homozygous kni ${ }^{F C 13}$ embryos (2 abdominal segments)

(Lehmann, 1985). (D),

Homozygous Df(3L)ri ${ }^{X T 1}$ embryo (Lehmann, 1985). Note identical abdominal phenotype to $k n i^{F C l 3}$ embryo although $\operatorname{Df}(3 \mathrm{~L}) r{ }^{\mathrm{XT} 1}$ embryo is deleted for both kni and knrl (Rothe et al., 1989). (E) Homozygous $k n i^{14 F}$ mutant embryo containing one copy of the suppressor Res ${ }^{1 r 1}$; note the wildtype segmentation pattern. (F)

Homozygous $\mathrm{kni}^{F C l 3}$ mutant containing one copy of $\operatorname{Res}^{1 r l}$; note the rescue of 2 abdominal segments. (G) Homozygous Df(3L)ri ${ }^{X T 1}$ mutant embryo containing one copy of $\operatorname{Res}^{1 r l}$ lacking the rescued abdominal segments as observed in F, indicating that rescue by the suppressor requires a gene, uncovered by the deficiency, which is likely to be knrl (see text).

the TM3 chromosome but not on the other chromosomes tested. The $R s p^{s}$-like locus on TM3 could have been generated by any one of the multiple inversions present on this chromosome, for instance. We have not been able to determine if kni is required to observe the chromosome segregation defect because $k n i^{14 F} \operatorname{Res}^{1} /+$ females mated to wildtype males do not produce any $\operatorname{Res}^{1}$ progeny that do not also have the kni mutation, apparently because these embryos have a bicaudal-like phenotype and are inviable. kni ${ }^{14 F} \operatorname{Res}^{1}$ I + females mated to wild-type males produce $k n i^{14 F} /+$ progeny at normal frequencies (approximately 20\%), indi- cating that there is not an inhibition of recombination between kni and Res. Circumstantial evidence that Res ${ }^{1}$ embryos are inviable because they have a bicaudal-like phenotype is that $k n i^{14 F} \operatorname{Res}^{1} / \mathrm{TM} 3$ females do not produce any bicaudal-like embryos, whereas kni ${ }^{14 F} \operatorname{Res}^{1} /+$ females produce $10-30 \%$ bicaudal-like embryos, which is approximately the frequency of recombination between these loci (Fig. 3). A more detailed genetic analysis of the chromosomal segregation distortion phenotype of $\operatorname{Res}^{1}$ is beyond the scope of the present paper, but will be presented later (D. M. R., unpublished data). 

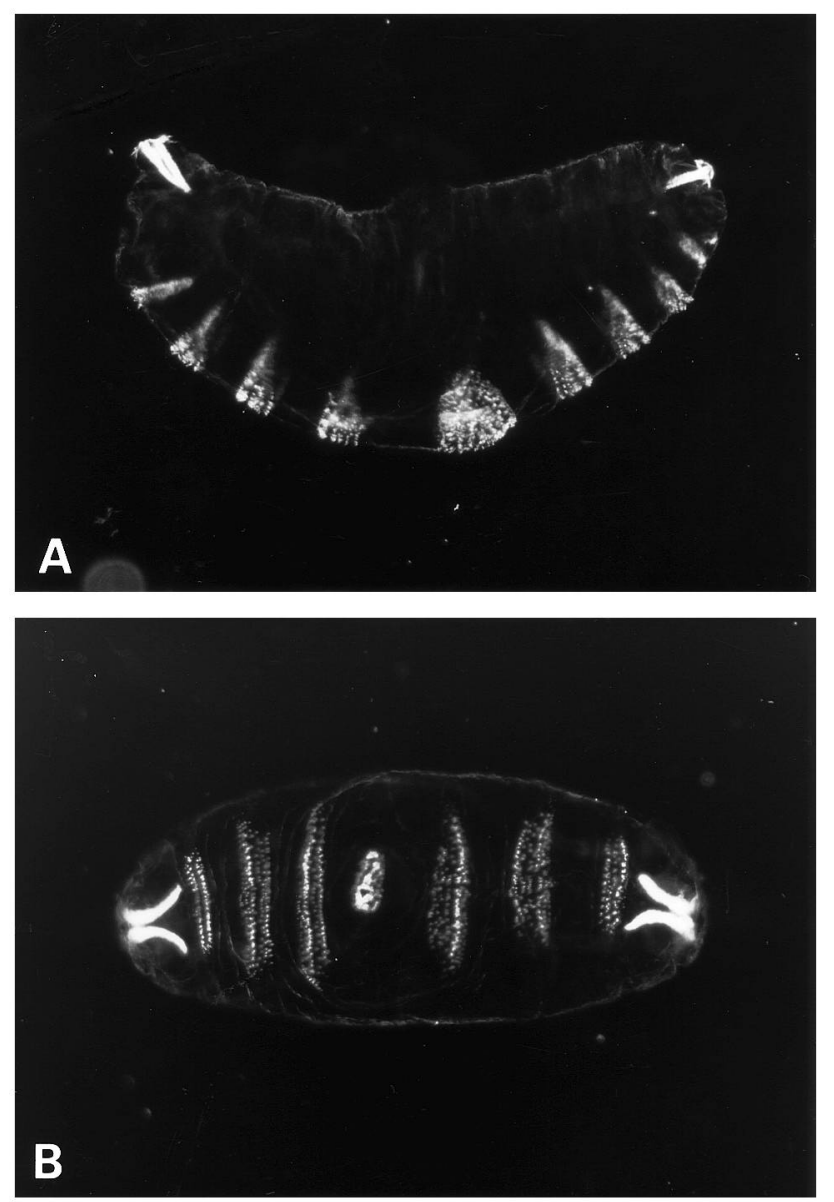

Fig. 2. Res $^{1}$ and God $^{l}$ females produce bicaudal-like embryos. (A) bicaudal-like embryo from a $k n i^{14 F} \operatorname{Res}^{1} /+$ female mated with an Oregon R male. (B) bicaudal-like embryo from a God / God ${ }^{1}$ female mated with an Oregon R male. The frequency of bicaudallike embryos in both crosses was approximately $10-30 \%$, depending on the age of the females. A large percentage of the embryos had a range of head-defect and asymmetrical bicaudal-like phenotypes similar to that described previously for bicaudal $^{l}$ (Nüsslein-Volhard, 1977; data not shown). As a control, $k n i^{14 F} /+$ females did not produce any bicaudal-like embryos out of over 1,000 embryos scored (data not shown).

\section{$G^{1}{ }^{1}$, a second dominant zygotic suppressor of a kni hypomorphic phenotype}

It is unwise to make all of ones conclusions on a single allele of a gene because that one allele might have atypical characteristics. With this in mind, we set out to isolate additional zygotic suppressors of $k n i^{14 F}$ by screening another $100,000 \mathrm{~F}_{1}$ progeny as described in Materials and Methods and isolated a second suppressor termed Godzillal $\left(\operatorname{God}^{l}\right)$. Table 2 shows that flies carrying a chromosome that contains both $k n i^{P 5}$ and $\mathrm{God}^{l}$ produce $k_{n i}{ }^{P 5} \operatorname{God}^{1} / k^{2} i^{F C l 3}$ progeny, regardless of whether $\operatorname{God}^{l}$ is provided maternally or paternally. The suppressor $\mathrm{God}^{l}$ is associated with a translocation with breakpoints at 60D1,2 and 98F1,2 involving the tips of the right arms of chromosomes 2 and 3, respectively (Fig. 3). The God ${ }^{l}$ translocation is homozygous viable and the second chromosome breakpoint is allelic with the blistered (bs) recessive
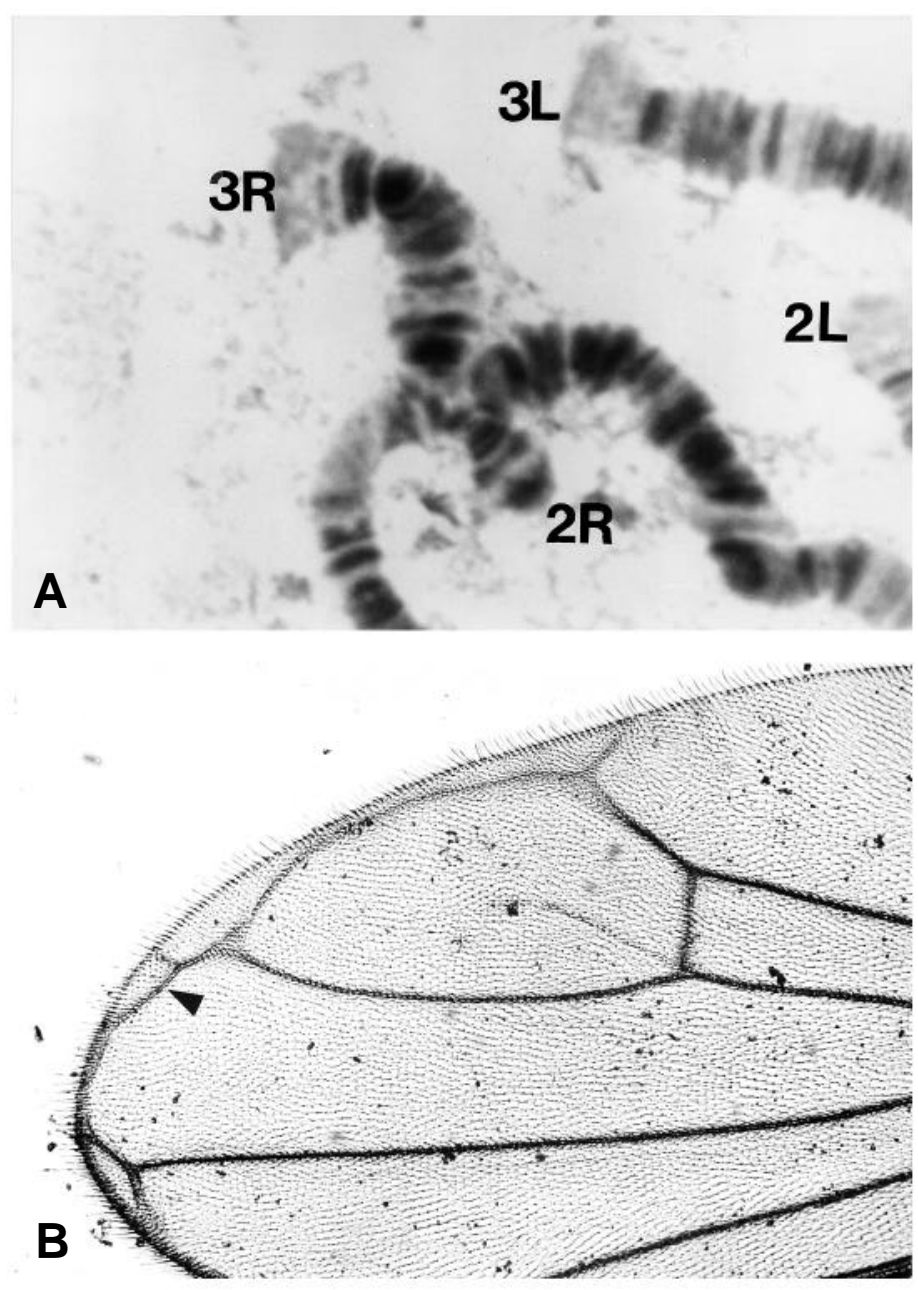

Fig. 3. $\operatorname{God}^{1}$ contains a chromosomal translocation and has a recessive wing-patterning phenotype. (A) Chromosome squash of $\operatorname{God}^{l} /+$ third instar salivary gland polytene chromosomes, prepared as described by Ashburner (1989). 2L, 2R, 3L, and 3R denote the ends of the second and third chromosomes. Note that the telomeric regions of $2 \mathrm{R}$ and $3 \mathrm{R}$ cross over each other. This crossover is seen in all preparations and indicates that, since homologous chromosomes are paired in polytene chromosomes, there is a translocation between the second and the third chromosomes at the crossover juncture (see text). (B) Wing of a fly homozygous for the $G o d^{l}$ translocation. Note the extra venous material at the wing margins (arrow). In wild-type wings, the distal parts of the veins continue uninterrupted to the margin (not shown).

complementation group (Fig. 3; see Materials and Methods). Females homozygous for the God $^{l}$ translocation produce embryos with a bicaudal-like phenotype similar to $\operatorname{Res}^{1}$. Note, however, that the bicaudal-like phenotype of embryos from $\operatorname{Res}^{1}$ mothers is the result of a dominant maternal mutation, whereas the bicaudal-like phenotype of embryos from God $^{l}$ mothers results from a recessive maternal mutation (Fig. 2). Finally, we timed nuclear divisions in $\operatorname{God}^{l}$ embryos and found that $\mathrm{God}^{1}$ slows down the 12 th mitotic cycle to a similar degree as $\operatorname{Res}^{1}$ : from about 13 minutes in wild-type embryos to about 18 minutes in God $^{l}$ embryos (Table 3). However, whereas the effect of $\operatorname{Res}^{1}$ was apparently specific for the 12th mitotic 
Table 2. God $^{1}$ rescues homozygous $k n i$ mutant embryos to fertile adults

\begin{tabular}{|c|c|c|c|c|c|c|}
\hline \multirow[b]{2}{*}{ Genotype of mating pairs* } & \multicolumn{6}{|c|}{$\mathrm{F}_{1}$ genotype ( $\%$ of surviving adults) $\dagger$} \\
\hline & $k n i^{P 5} / k_{n i}^{F C 13}$ & $k n i^{P 5} / T M 3$ & $k n i^{F C 13} / T M 3$ & $\mathrm{kni}^{P 5} \mathrm{God}^{\mathrm{l}} / \mathrm{kni}^{\mathrm{FCl3}}$ & $\mathrm{kni}^{P 5} \mathrm{God}^{l} / \mathrm{TM} 3$ & $+/ C y O ; k n i^{F C l 3} / T M 3$ \\
\hline$k_{n i}{ }^{P 5} / T M 3$ ơ $\times k n i^{F C l 3} / T M 3 q$ & 0 & $47.4 \pm 5.5$ & $52.6 \pm 5.5$ & - & - & - \\
\hline '+'/CyO;kni ${ }^{P 5} G^{\prime} d^{I} / T M 3$ oิ $\times k i^{F C l 3} / T M 3$ q & - & - & - & $1.3 \pm 1.5 \ddagger$ & $53.0 \pm 4.0$ & $47.0 \pm 4.0 \S$ \\
\hline 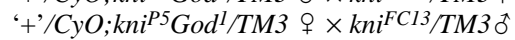 & - & - & - & $1.7 \pm 1.2 \ddagger$ & $55.7 \pm 8.6$ & $44.3 \pm 8.6 \S$ \\
\hline
\end{tabular}

*See Materials and Methods for exact genotypes. A single male was mated to two virgins at $25^{\circ} \mathrm{C}$ as described in Table 1. '+' is not a wild-type chromosome but rather contains a translocation between the second and third chromosomes (see below and Fig. 3A).

$\dagger$ The $F_{1}$ genotypes, their distribution, and standard deviations are shown from ten sets of flies that produced $\geq 30 \mathrm{~F}_{1}$ progeny. Total number of scored $\mathrm{F}_{1}$ progeny is 819 (top row), 606 (second row), and 544 (third row).

$\$$ God $^{l}$ allows survival of kni-mutant homozygous adults. These stocks are fertile but have low viability and cannot be maintained as stocks.

$\S$ Note that the TM3 and CyO balancer chromosomes from the God $^{l}$ parent co-segregate in $100 \%$ of the progeny. The explanation for this is that God ${ }^{l}$ contains a translocation between $2 \mathrm{R}$ and $3 \mathrm{R}$ and, since the telomeric regions are haploinsufficient, the second and the third chromosomes bearing this translocation cannot be inherited individually but must cosegregate (see text).

Table 3. $\operatorname{Res}^{1}$ and $\operatorname{God}^{1}$ embryos have longer blastoderm nuclear cycle(s) than wild type

\begin{tabular}{lccc}
\hline \multirow{2}{*}{$\begin{array}{l}\text { Genotype of } \\
\text { parents }\end{array}$} & \multicolumn{3}{c}{ Nuclear cycle (minutes)* } \\
\cline { 2 - 4 } & 11 & 12 & 13 \\
\hline Wild type $\dagger$ & $11.0 \pm 1.3$ & $12.8 \pm 0.8$ & $20.0 \pm 1.7$ \\
knil $^{14 F}$ Res $^{l} / T M 3 \ddagger$ & $10.8 \pm 1.2$ & $18.1 \pm 1.2$ & $19.3 \pm 1.7$ \\
God $^{l} /$ God $^{l} \S$ & $10.6 \pm 1.1$ & $17.8 \pm 0.8$ & $25.3 \pm 2.0$
\end{tabular}

*For the exact genotype of the parents, see Materials and Methods. Timing and photographic analysis was started at the beginning of mitotic cycle 11 when the 8 pole cells pinch off from the main body of the embryo and was continued until the middle of mitotic cycle 14 when cellularization occurs. The estimated length of the 11-13th mitotic cycles (10, 12, and 21 minutes, respectively; Foe and Alberts, 1983) represents mean values obtained from ten individually staged embryos; the standard deviations are shown. For handling of embryos see Materials and Methods.

†Oregon-R.

$\ddagger$ See Materials and Methods for exact genotype. We note that two out of the ten embryos scored in this cross had wild-type length 12th mitotic cycles and eight had extended 12th mitotic cycles (data not shown). These two embryos with wild-type length 12th mitotic cycles are presumably TM3balancer homozygous embryos and therefore do not contain $\operatorname{Res}^{l}$.

$\S G_{o d}{ }^{l}$ translocation homozygous females were crossed to God $^{l}$

translocation homozygous males to ensure that all of the embryos in this cross are genotypically identical (see Materials and Methods).

cycle, $\operatorname{God}^{1}$ also slows down the 13th mitotic cycle from about 20 minutes in wild-type embryos to about 25 minutes in God $^{1}$ embryos. Since the chromosomal breakpoint at the third chromosome is near the genetic map location of $\operatorname{Res}^{l}$, and since both $\operatorname{Res}^{1}$ and $\operatorname{God}^{l}$ mothers produce embryos with bicaudallike phenotypes, and since both $\operatorname{Res}^{1}$ and $\operatorname{God}^{1}$ slow down the 12th mitotic cycle to a similar extent, it is probable that $\operatorname{Res}^{1}$ and $\operatorname{God}^{1}$ are allelic. However, unlike $\operatorname{Res}^{1}, \operatorname{God}^{1}$ did not show a meiotic drive-like chromosome segregation defect, possibly because it is a weaker allele (Table 2).

\section{$\boldsymbol{R e s}^{\mathbf{1}}$ requires $\mathbf{k n r l}$ for suppressor function}

When doing suppressor analysis in any system, it is important to determine the allele specificities of the suppressors to facilitate the determination of suppressor function (Jarvik and Botstein, 1975). As described in a previous section, $\operatorname{Res}^{1}$, when present in one copy, allows the normally lethal kni ${ }^{14 F}$ homozygous embryos to develop a normal segmentation pattern (Fig. $1 \mathrm{E})$ and to survive as adults (Table 1). Furthermore, $k n i^{14 F}$ homozygous flies can be propagated as fertile stocks when one copy of $\operatorname{Res}^{1}$ is present in the genome (Table 1). However, the removal of the $\operatorname{Res}^{1}$ mutation from the $k n i^{14 F}$ chromosome by genetic recombination restores the $k n i^{14 F}$ embryonic lethal phenotype, thus indicating that the phenotypic rescue and the survival of $k n i^{14 F}$ mutant embryos is critically dependent on the $\operatorname{Res}^{1}$ mutation.

In order to determine the allele specificity of Res, we used the weakened derivative of $\operatorname{Res}^{1}$, termed $\operatorname{Res}^{1 r l}$ (see above and Materials and Methods). When $\operatorname{Res}^{1 r l}$ is recombined onto the $k n i^{F C l 3}$ chromosome from which no kni mRNA or protein is produced (Nauber, 1988; Gerwin et al., 1994), the segmentation phenotype of the $k n i^{F C 13} \operatorname{Res}^{1 r l}$ double mutant embryos is partially rescued and one or two additional abdominal segments are present (compare Fig. 1C,F). This partial rescue of a kni lack-of-function mutation indicates that the suppressor mutation does not specifically act upon the truncated $k n i^{14 F}$ protein since the suppressor does not require the presence of any kni protein to provide partial segmentation activity. The suppressor must therefore act through another gene which in turn overcomes the defects caused by $k n i^{14 F}$.

One likely candidate for a gene that partially restores the function of kni in Res ${ }^{1}$ embryos is the kni cognate gene knrl. Previous analysis has shown that a knrl cDNA transgene expressed from a kni promoter is able to restore up to two abdominal segments in embryos lacking a functional kni gene (Rothe et al., 1992), which is approximately the amount of segmentation activity provided by the suppressor in kni lack-offunction homozygous embryos (Fig. 1F). If the suppressor were to function by activating the kni-like segmentation property of $k n r l$, the abdominal segmentation pattern should not be restored in $\operatorname{Df}(3 \mathrm{~L}) r i{ }^{X T 1}$ embryos which are deleted for both the kni and knrl genes (Lehmann, 1985; Rothe et al., 1992). Df(3L)ri ${ }^{X T 1}$ homozygous embryos show no restoration of the abdominal segments in the presence of one copy of the suppressor (compare Fig. 1D,G). Thus it appears likely that the activity of knrl or another gene contained within Df(3L)ri ${ }^{X T 1}$ is required to restore suppressor-dependent abdominal segmentation in kni embryos.

In order to examine whether knrl rather than another gene within the deficiency Df(3L)ri ${ }^{X T 1}$ provides the $\operatorname{Res}^{1}$-dependent rescue of the kni mutants, we analyzed the temporal expression of $k n r l$ full-length transcript using RNA-PCR analysis on single, individually staged embryos (Foley et al., 1993; Fig. 4). Because of increased sensitivity, RNA-PCR analysis was chosen over the previously described in situ hybridization technique for detecting knrl mRNA (Rothe et al., 1992). PCR 
primers were made flanking introns at the $5^{\prime}$ and $3^{\prime}$ ends of the knrl gene, and a reverse transcription reaction was done before PCR amplification so that knrl transcripts could be distinguished from genomic DNA (see Materials and Methods). As shown in Fig. 4C, the 5' end of the knrl transcript was initially detected in cycle 12 in both wild-type and $k n i^{14 F} \operatorname{Res}^{1}$ embryos; whereas, the processed 3'-portion of $k n r l$ mRNA, which was initially detected in mitotic cycle 13 of wild-type embryos, can already be detected in mitotic cycle 12 in $k n i^{14 F} \operatorname{Res}^{1}$ embryos (Fig. 4C). This demonstrates that the presence of $\operatorname{Res}^{1}$ causes a longer, and presumably full length, mRNA product of knrl.

\section{$\operatorname{Res}^{1}$ slows down blastoderm mitotic cycles}

$\operatorname{Res}^{1}$-dependent revival of $k n r l$ could be due to lengthening of the mitotic cycle or to a specific effect that prevents the abortion of nascent transcripts between mitotic cycles (Shermoen and O'Farrell, 1991). In order to distinguish between these two possibilities, we examined the length of mitotic cycles in $\operatorname{Res}^{l}$ as compared to wild-type embryos. Timing of nuclear divisions in living embryos shows that $\operatorname{Res}^{1}$ causes a specific extension of cycle 12 from about 13 minutes in wild-type embryos to about 18 minutes in $\operatorname{Res}^{1}$ embryos (Table 3). At a transcription rate of $1.4 \mathrm{~kb} /$ minute (Shermoen and O'Farrell, 1991), the synthesis of the 23 kb knrl primary transcript would take about 16 minutes. Thus, 18 minutes would be sufficient to allow the complete transcription of $\mathrm{knrl}$, consistent with the detection of spliced 3' portion of $\mathrm{knrl}$ mRNA at cycle 12 in Res $^{1}$ embryos (Fig. 4C).

\section{$\operatorname{Res}^{1}$ embryos have chromosome segregation defects}

A large class of cell cycle mutations in both yeast and Drosophila are those that cause defects or arrest at one particular stage of the mitotic cycle (Hartwell and Weinert, 1989; Nurse, 1990). To determine if $\operatorname{Res}^{1}$ embryos are defective in any stage of the mitotic cycle, we stained fixed $\operatorname{Res}^{1}$ embryos with the fluorescent dye Hoechst 33258, which stains DNA, and found that more embryos in the 11-13th mitotic cycles were in metaphase where the chromosomes are lined up on the

A

B

C metaphase plate: $10 \%(11 / 105)$ of wild-type embryos and $22 \%$ (24/110) of $\operatorname{Res}^{1}$ were in metaphase (Fig. 5B). Another feature
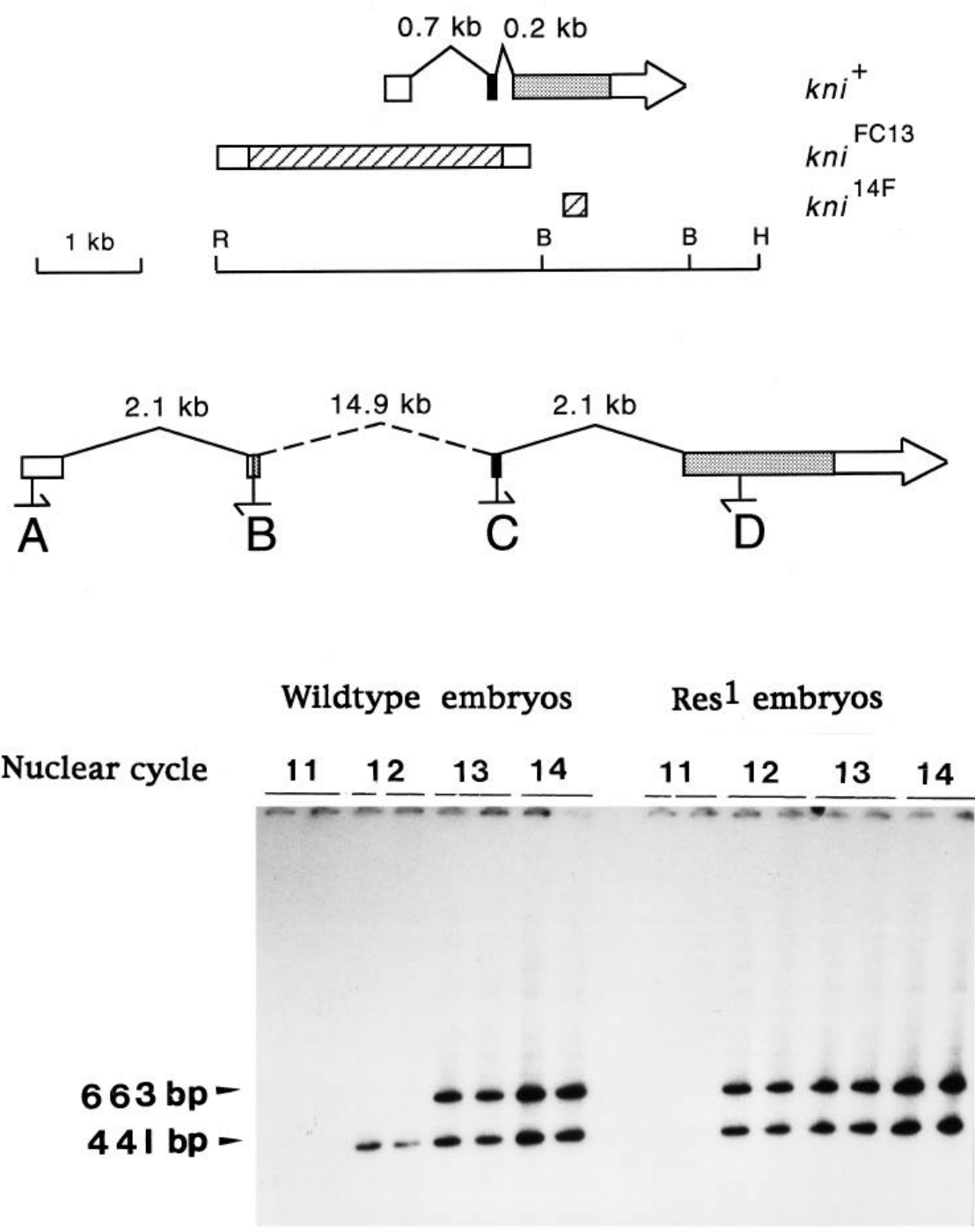

Fig. 4. A longer knrl transcript is detected in cycle 12 in $\operatorname{Res}^{1}$ embryos as compared with wild-type embryos. (A) Organization of the kni transcription unit (comprises about $3 \mathrm{~kb}$; numbers indicate positions and size of introns; arrow, direction of transcription; open bars, untranslated sequences; filled bars, first zinc-finger exon; stippled bars, coding regions; hatched bars, DNA sequences deleted in the $k n i^{14 F}$ and $k n i^{F C 13}$ alleles). At the bottom is a restriction map (R, EcoRI; B, BamHI; H, HindIII). Note that the $k n i^{14 F}$ allele contains only the amino-terminal 232 amino acids out of 429 amino acids in wild type and the region $3^{\prime}$ to the deletion contains 105 frameshifted amino acids (Gerwin et al., 1994). The approximately $2.0 \mathrm{~kb}$ long $\mathrm{kni}^{\mathrm{FCl3}}$ deficiency deletes the first finger exon and promoter sequences; no kni mRNA is produced (Nauber et al., 1988). (B) Organization of the knrl transcription unit which comprises approximately $23 \mathrm{~kb}$ of DNA (Rothe et al., 1989). The positions and directions of the primers used for RNA-PCR analysis are indicated (A, B, C, and D). (C) RNA-PCR analysis of $5^{\prime}$ and $3^{\prime}$ portions of knrl mRNA from single embryos in late mitotic cycle $11,12,13$, and at cellularization in mitotic cycle 14 . Analysis at each mitotic cycle is shown in duplicates. (Wild-type embryos: Oregon R; $\operatorname{Res}^{1}$ embryos: embryos from parents that were $s t k n i^{14 F} p^{p} \operatorname{Res}^{1} /$ TM3,Sb and had a lengthened 12th mitotic cycle). 441 bp: amplification of a spliced 5' portion between primers A and B; 663 bp: spliced 3' portion of $k n r l$ mRNA between primers $\mathrm{C}$ and $\mathrm{D}$. The spliced 3' portion of $k n r l$ is produced during late mitotic cycle 12 embryos bearing the $\operatorname{Res}^{1}$ mutation, but not until late mitotic cycle 13 in wild-type embryos. Note that the PCR product of the genomic DNA would be $2.1 \mathrm{~kb}$ longer in each case (because of intron sequences); their absence serves as an indication that knrl mRNA rather than knrl genomic DNA was amplified. 

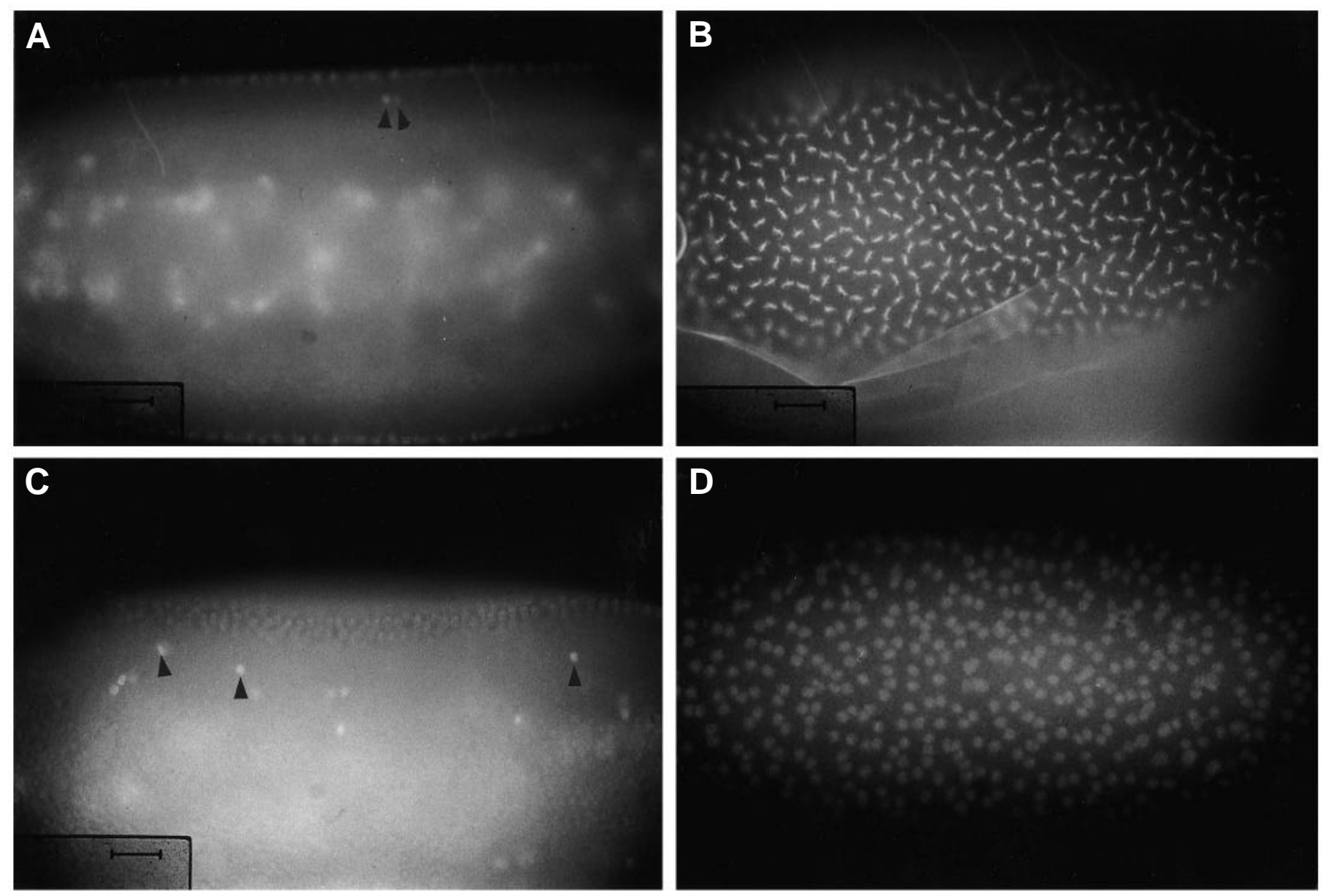

Fig. 5. $\operatorname{Re}^{l}$ has a nuclear holes phenotype and interacts genetically with $t h r^{l}$. (A) A typical embryo from the stock $k n i^{14 F} \operatorname{Res}^{1} / \mathrm{TM}^{\mathrm{T}}, \mathrm{Sb}$ fixed and stained with Hoechst 33258 (Knoblich and Lehner, 1993). Note the two nuclei that have dropped out of the periphery (arrowheads). A $10 \mu \mathrm{m}$ scale bar is shown. (B) The same embryo as in A but seen as a surface optical section. (C) A typical embryo from the cross $t h r^{l} /+; \operatorname{Res}^{1} /+$, double heterozygous females mated to wild-type males. Note the large number of nuclei that have dropped out of the periphery (three of these are indicated by arrowheads). (D) The same embryo as in C but seen as a surface optical section. Note that the pattern of nuclei is irregular. As controls, $t h r^{l} /+$ females and $\operatorname{Res}^{l} /+$ females did not produce this nuclear holes phenotype (data not shown; see text).

of $\operatorname{Res}^{1}$ embryos revealed by Hoechst staining is that they have nuclei that have dropped out of the periphery into the interior of the embryo during mitotic cycles 11-13 (Fig. 5A). The dropping out of nuclei was first described for the maternal effect mutation daughterless-abnormal-oocyte-like (dal) and is thought to be a characteristic of nuclei that have failed to perform proper sister chromosome segregation (Sullivan et al., 1990). The zygotic mitotic cycle regulatory mutation threerows $^{l}\left(t h r^{l}\right)$ also shows a dropping out of nuclei in the 11-13th mitotic cycles, which is similar to that observed with $\operatorname{Res}^{1}$, although the terminal phenotype of $t h r^{l}$ is not observed until the 15th mitotic cycle, which fails to undergo mitosis (Philp et al., 1993).

It was previously shown that cell cycle mutations that are involved in similar or redundant processes synergistically enhance each others phenotypes (Edgar et al., 1994; Fitch et al., 1992). Because of the similar zygotic phenotypes of $t \mathrm{hr}^{l}$ and $\operatorname{Res}^{1}$, we wanted to determine if there was a synergistic interaction between these mutations. Females that are double heterozygous for $t h r^{l}$ and $\operatorname{Res}^{l}$ do not produce viable embryos. These embryos have severe chromosome segregation defects in the 11-13th mitotic cycles as revealed by a large number of nuclei dropping out of the periphery (Fig. 5C,D). Females that are heterozygous for either $t h r^{I}$ or $\operatorname{Res}^{1}$ alone produce embryos in which very few, if any, nuclei drop out from the periphery during the 11-13th mitotic cycles (data not shown). This experiment, therefore, demonstrates that there is a strong synergistic interaction between $t h r^{l}$ and $\operatorname{Res}^{l}$ and suggests that the products of these two genes have similar functions (see Discussion).

\section{Females heterozygous for a deficiency of the cyclin $B$ locus suppress the kni mutant phenotype}

Edgar et al. (1994) have recently shown that females heterozygous for a deficiency of the cyclin $B$ locus, or more dramatically, double heterozygous for a mutation in cyclin $A$ and a deficiency of the cyclin $B$ locus, have slower 11-13th mitotic cycles. Since we argue that $\operatorname{Res}^{1}$ and $\operatorname{God}^{1}$ function as kni suppressors by slowing down blastoderm mitotic cycles, we wanted to determine whether females heterozygous for mutations in either cyclin $A$, or cyclin $B$, or double heterozygous for mutations in both cyclin $A$ and $c y c l i n B$ will support 
Table 4. A maternal Cyclin B mutation rescues homozygous kni mutant embryos to fertile adults

\begin{tabular}{|c|c|c|}
\hline \multirow[b]{2}{*}{ Genotype of mating pairs* } & \multicolumn{2}{|c|}{$\begin{array}{c}\mathrm{F}_{1} \text { genotype } \\
(\% \text { of surviving adults }) \dagger\end{array}$} \\
\hline & $k n i^{P 5} / k_{n i} i^{F C 13} \ddagger$ & $\begin{array}{l}\text { All other } \\
\text { genotypes§ }\end{array}$ \\
\hline$C y c B /+; k n i^{P 5} /+$ ठิ $\times k n i^{F C l 3} / T M 3$ q & 0 & 100 \\
\hline$C y c B /+; k n i^{P 5} /+q \times k n i^{F C 13} / T M 3$ ठे & $12.3 \pm 4.9$ & $87.7 \pm 4.9$ \\
\hline$C y c B /+; k n i^{F C 13} / T M 3$ o $\times k n i^{P 5} / T M 3$ ㅇ & 0 & 100 \\
\hline$C y c B /+; k n i^{F C 13} / T M 3$ 우 $\times k n i^{P 5} / T M 3$ oิ & $12.6 \pm 2.7$ & $87.4 \pm 2.7$ \\
\hline$k n i^{P 5} / C y c A$ o $\times k n i^{F C 13} / T M 3$ o & 0 & 100 \\
\hline$C y c B /+; k n i^{P 5} / C y c A$ oे $\times k n i^{F C 13} / T M 3$ q & 0 & 100 \\
\hline$C y c B /+; k n i^{P 5} / C y c A$ ㅇ $\times k n i^{F C 13} / T M 3$ ô & $21.6 \pm 3.3$ & $78.4 \pm 3.3$ \\
\hline \multicolumn{3}{|c|}{ 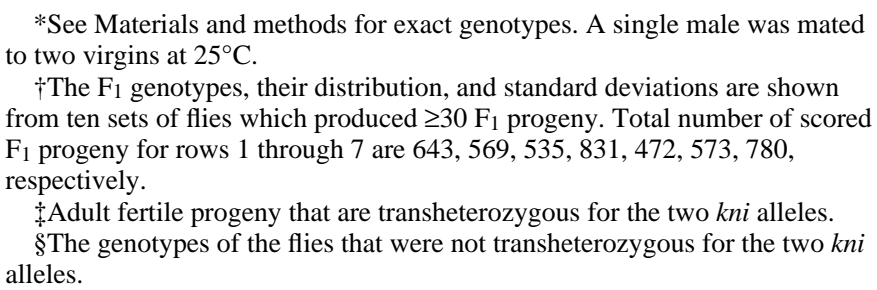 } \\
\hline
\end{tabular}

the production of viable kni transheterozygous mutant progeny. Table 4 shows that females that have only one copy of cyclin $B$ will produce approximately $12 \% k_{n i} i^{P 5} / k^{F C 13}$ adult progeny, whereas no $k n i^{P 5} / k_{n i} i^{F C 13}$ adult progeny are produced from females that are wild-type for cyclin $B$. This effect of kni suppression by a heterozygous deficiency of the cyclin $B$ locus is strictly maternal because males that are heterozygous for cyclin $B$ do not produce any $k n i^{P 5} / k^{2} i^{F C 13}$ adult progeny (Table 4). It did not matter whether the mother provides the strong or the weak allele of kni (Table 4), a result that is consistent with the previous analysis of kni showing that kni mutants have no maternal effect (Lehmann, 1985). Unlike cyclin $B$, heterozygosity for cyclin $A$ is not sufficient for females to produce viable homozygous kni mutant progeny. Females double heterozygous for both cyclin $A$ and cyclin $B$, however, produce almost twice as many homozygous kni mutant adult progeny (approximately 22\%) than do females that are heterozygous for cyclin $B$ alone (Table 4; see Discussion). The increased efficiency in suppressing kni when females are double heterozgygous for both cyclin A and cyclin $B$ is consistent with the previous conclusion that these cyclins interact with each other synergistically and provide similar functions (Lehner and O'Farrell, 1990; Knoblich and Lehner, 1993; Edgar et al., 1994).

\section{DISCUSSION}

By isolating zygotic suppressors of kni, we identified mutations that slow down blastoderm mitotic cycles and thereby allow precocious expression of $\mathrm{knrl}$, a gene whose transcript is normally too large to be fully transcribed during this period (Rothe et al., 1992). knrl, upon precocious expression, provides weak kni-like functions and leads to a suppression of the kni mutant phenotype. This technique of mitotic delay dependent survival promises to serve as a powerful tool to identify mitotic cycle control genes. In the following sections, we discuss some of the implications of our work.

\section{What might the selfish phenotype of $\boldsymbol{R e s}^{1}$ signify? $^{2}$}

The low frequency of obtaining zygotic suppressors of kni might reflect the finding that all of the known mitotic cycle regulatory proteins and mRNAs are provided maternally and that the transcription of these genes is not re-initiated zygotically until the 14th mitotic cycle (Edgar et al., 1994). Since the phenocritical period of kni function includes the 12 th mitotic cycle as shown by the specific effect of the $\operatorname{Res}^{1}$ mutation on knrl transcription during this mitotic cycle (Fig. 4), a mutation that affects the zygotic activity of a mitotic cycle gene should therefore not affect early kni expression. Furthermore, inhibition of mRNA synthesis by injection of $\alpha$-amanitin does not prevent the embryo from undergoing the first 13 nuclear divisions at approximately normal times, indicating that synthesis of proteins from zygotic transcripts should not affect these early mitotic divisions (Edgar et al., 1986). Therefore, contrary to the results presented here, one could reasonably say that it is hypothetically impossible to obtain zygotic kni suppressors.

The fact that $\operatorname{Res}^{1}$ has also a 'selfish' chromosome segregation phenotype in which the $\operatorname{Res}^{l}$ chromosome is inherited in over $99 \%$ of the progeny suggests an imprinting mechanism as a way to circumvent the hypothetical impossibility of obtaining zygotic kni suppressors (Table 1; Dawkins, 1989). If $\operatorname{Res}^{1}$ were a chromatin component in both male and female germ cells, for instance, then the parentally provided $\operatorname{Res}^{l}$ product could slow down the blastoderm mitotic cycles by interfering with the segregation of sister chromosomes in the embryo. In other words, according to this hypothesis, it is either the paternal or the maternal expression of $\operatorname{Res}^{1}$, rather than the zygotic expression, which allows suppression of the kni phenotype. The selfish chromosome segregation phenotype of $\operatorname{Res}^{1}$ is similar to the chromosome segregation phenotype of Segregation distorter $(S d)$, whose product is also thought to be a germ cell chromatin component (McLean et al., 1994). Unlike Res ${ }^{l}$, however, the $S d$ chromosome is inherited in a majority of the progeny only when it is transmitted through the male germ line (Lyttle, 1993).

Consistent with the speculation that $\operatorname{Res}^{1}$ is a chromatin component involved in sister chromosome segregation is the fact that $\operatorname{Res}^{1}$ mutant embryos show a chromosome segregation defect in which blastoderm nuclei drop into the interior of the embryo (Fig. 5A). This phenotype is called 'nuclear holes' because of an asymmetrical pattern of nuclei in a surface optical section of these embryos (Fig. 5B). The mitotic cycle regulatory gene $t h r$, which has a region of homology with the nuc2 gene of Schizosaccharomyces pombe whose product is thought to be involved in packaging chromatin into nuclear scaffolds (Hirano et al., 1988 and 1990), interacts genetically with $\operatorname{Res}^{1}$ (Fig. 5C,D), and also shows the nuclear holes phenotype during the 11-13th mitotic cycle (Philp et al., 1993). Since embryos laid by $\operatorname{Res}^{1}$ and $t h r^{1}$ double heterozygous females show a severe nuclear holes phenotype, the corresponding wild-type functions are likely to be involved in similar processes. An interesting speculation is that Res and thr are protein components which must be proteolized before sister chromosome separation and that the Res ${ }^{1}$ product is less efficiently proteolized than the wild-type protein (Holloway et al., 1993; Cooke et al., 1987; Rattner et al., 1988). This low efficiency in Res $^{1}$ proteolysis could explain the observed mitotic cycle delay observed with $\operatorname{Res}^{1}$ embryos (Table 3). 
Also consistent with the speculation that $\operatorname{Res}^{1}$ is a chromatin component involved in sister chromosome segregation is the observation that twice as many $\operatorname{Res}^{1}$ embryos than wild-type embryos in the 11-13th mitotic cycle have metaphase figures. We note that this result does not argue against the general hypothesis that the mitotic delay allows full-length transcription of knrl because Shermoen and O'Farrell (1991) observed that transcription (as revealed by nuclear dots) occurs during the metaphase cycle and gradually decreases during metaphase, anaphase, and telophase. They speculate that transcriptional abortion is a slow and multi-step process like normal termination of transcription which requires passage of polymerase through a poly(A) addition site and downstream termination (Shermoen and O'Farrell, 1991).

\section{Why do Res ${ }^{1}$ and God $^{1}$ females produce bicaudal- like embryos?}

It is possible that the bicaudal-like maternal phenotypes of $\operatorname{Res}^{l}$ and $\operatorname{God}^{l}$ are a manifestation of their interaction with the mitotic cycle machinery. It is known that the microtubule cytoskeleton is involved in the transport of the posterior determinants (Theurkauf et al., 1993; Clark et al., 1994). It is also known that cyclin $A$ and cyclin $B$ double heterozygous females produce embryos with a reduced density microtubule cytoskeleton (Baker and Schubiger, 1994). Therefore, if $\operatorname{Res}^{1}$ or $\operatorname{God}^{l}$ females, like cyclin $A$ and cyclin B double heterozygous females, also produce embryos in which the integrity of the microtubule cytoskeleton is affected, the resultant embryos could have a bicaudal-like phenotype because a posterior determinant is not efficiently transported to the posterior of the embryo (see Wharton and Struhl, 1989). Genetic support for the hypothesis that mitotic regulatory mutations can affect the transport of the posterior determinants is that females double heterozygous for both a deficiency of the cyclin $B$ locus and Bicaudal $D(B i c D)$ produce a much higher frequency of bicaudal-phenotype embryos than do females heterozygous for $B i c D$ alone (D. M. R., unpublished data). It is known that embryos from BicD mothers have defects in the transport of the posterior determinants (Wharton and Struhl, 1989) and, presumably, the cyclin $B$ mutation enhances the BicD phenotype by affecting the integrity of the microtubule cyctoskeleton in these embryos. Since there are no mitotic divisions during the post-germarium stages of oogenesis when the posterior determinants are localized, our results suggest that the mitotic regulatory components are also involved in the organisation of the microtubule cytoskeleton during oogenesis (Thaurkauf et al., 1993).

\section{Evolutionary implications}

In addition to the cell cycle regulatory aspects of $\operatorname{Res}^{1}$ and $\operatorname{God}^{1}$, there are important evolutionary aspects of their function because they suppress kni by restoring the function of the cognate gene knrl. It had been argued that kni and knrl derived by gene duplication from a common ancestral gene which functioned not only in segmentation but also in a number of tissues at post-blastodermal stages of Drosophila development (Rothe et al., 1992). It is possible that kni has adapted to the extremely rapid development of Drosophila by losing intron sequences whereas knrl could act only at later stages when the cell cycles are long enough to synthesize the primary transcript. This would allow, in evolutionary terms, a drift of the two genes to adopt different but partially overlapping functions, providing a simple explanation for what leads to partial or complete redundancy of gene activities, a phenomenon revealed by gene knock-outs in mammals (Thomas and Capecchi, 1990; Joyner et al., 1991; Lohnes et al., 1993; McMahon and Bradley, 1990). The finding that a cognate gene can be revived by a mutation at a single genetic locus indicates that supposedly silent genes represent a reservoir for the ability to compensate for mutational events or to counter sudden changes of evolutionary constraints by recruiting hidden gene activities into function (Thomas, 1993). The possibility of such a recruitment in response to selective genetic pressures as shown here, or environmental stress, may represent an important mechanism involved in speciation and evolution.

We thank X. Lu, R. Cohen, G. Dowe, M. González-Gaitán, M. Rothe, S. Sugiyama, M. Pankratz, U. Nauber, R. Lehmann, G. Jürgens, M. Hahn, R. Schuh, C. Hartmann and E. Vetter for their contributions. This work was supported by the Max Planck Society and the Deutsche Forschungsgemeinschaft. D. M. R. was an EMBO and NSF-NATO postdoctoral fellow.

\section{REFERENCES}

Ashburner, M. (1989). Drosophila, a Laboratory Handbook Cold Spring Harbor, New York: Cold Spring Harbor Laboratory Press.

Baker, J. and Schubiger, G. (1994). The cell cycle as a control of early development. In 35th Annual Drosophila Research Conference Genetics Society of America, Chicago.

Ballinger, D. G. and Benzer, S. (1989). Targeted gene mutations in Drosophila. Proc. Natl. Acad. Sci. USA 86, 9402-9406.

Berger, S. L., Pina, B., Silverman, N., Marcus, G. A., Agapite, J., Regier, J. L., Triezenberg, S. J. and Guarente, L. (1992). Genetic isolation of ADA2: A potential transcriptional adapter required for function of certain acidic domains. Cell 70, 251-265.

Clark, I., Giniger, E., Ruohola-Baker, H., Jan, L. Y. and Jan, Y. N. (1994). Transient posterior localization of a kinesin fusion protein reflects anteroposterior polarity of the Drosophila oocyte. Current Biol. 4, 289-300.

Cooke, C. A., Heck, M. M. S. and Earnshaw, W. C. (1987). The inner centromere protein (INCENP) antigens: movement from inner centromere to midbody during mitosis. J. Cell Biol. 105, 2053-2067.

Dawkins, R. (1989). The Selfish Gene. New Edition. Oxford: Oxford University Press.

Edgar, B. A., Sprenger, F., Duronio, R. J., Leopold, P. and O'Farrell, P. H. (1994). Distinct molecular mechanisms regulate cell cycle timing at successive stages of Drosophila embryogenesis. Genes Dev. 8, 440-452.

Edgar, B. A., Kiehle, C. P. and Schubiger, G. (1986). Cell cycle control by the nucleo-cytoplasmic ratio in early Drosophila development. Cell 44, 365372 .

Fitch, I., Dahmann, C., Surana, U., Amon, A., Nasmyth, K., Goetsch, L., Byers, B. and Futcher, B. (1992). Characterization of four B-type cyclin genes of the budding yeast Saccharomyces cerevisiae. Mol. Biol. Cell 3, 805818 .

Foe, V. E. and Alberts, B. (1983). Studies of nuclear and cytoplasmic behavior during the five mitotic cycles that precede gastrulation in Drosophila embryogenesis. J. Cell Sci. 61, 31-70.

Foe, V. E. (1989). Mitotic domains reveal early commitment of cells in Drosophila embryos. Development 107, 1-22.

Foley, K. P., Leonard, M. W. and Engel, J. D. (1993). Quantitation of RNA using the polymerase chain reaction. Trends Genet. 9, 380-385.

Gerwin N., LaRosée, A., Sauer, F., Halbritter, H.-P., Neumann, M., Jäckle, H. and Nauber, U. (1994). Functional and conserved domains of the Drosophila transcription factor encoded by the segmentation gene knirps. Molec. Cell. Biol. (in press).

Gubb, D. (1986). Intron-delay and the precision of expression of homeotic gene products in Drosophila. Dev. Genet. 7, 119-131.

Hartwell, L. H. and Weinert, T. A. (1989). Checkpoints: Controls that ensure the order of cell cycle events. Science 246, 629-634.

Himmelfarb, H. J., Pearlberg, J., Last, D. H. and Ptashne, M. (1990). 
GAL11P: A yeast mutation that potentiates the effect of weak GAL4-derived activators. Cell 63, 1299-1309.

Hirano, T., Hiraoka, Y. and Yanagida, M. (1988). A temperature-sensitive mutation of the Schizosaccharomyces pombe gene $n u c 2^{+}$that encodes a nuclear scaffold-like protein blocks spindle elongation in mitotic anaphase. J. Cell Biol. 106, 1171-1183.

Hirano, T., Kinoshita, N., Morikawa, K. and Yanagida, M. (1990). Snap helix with knob and hole: essential repeats in $S$. pombe nuclear protein $n u c 2^{+}$. Cell 60, 319-328.

Holloway, S. L., Glotzer, M., King, R. W. and Murray, A. W. (1993). Anaphase is initiated by proteolysis rather than by the inactivation of maturation-promotion factor. Cell 73, 1393-1402.

Jarvik, J. and Botstein, D. (1975). Conditional-lethal mutations that suppress genetic defects in morphogenesis by altering structural proteins. Proc. Natl. Acad. Sci. USA 72, 2738-2742.

Joyner, A. L., Herrup, K., Anerback, B. A., Davis, C. A. and Rossant, J. (1991). Subtle cerebellar phenotype in mice homozygous for a targeted deletion of the En-2 homeobox. Science 251, 1239-1243.

Kimble, M., Dettman, R. W. and Raff, E. (1990). The $\beta 3$-tubulin gene of Drosophila melanogaster is essential for viability and fertility. Genetics $\mathbf{1 2 6}$, 991-1005.

Knoblich, J. A. and Lehner, C. F. (1993). Synergistic action of Drosophila cyclins $A$ and $B$ during G2-M transition. EMBO J. 12, 65-74.

Lehmann, R. (1985).Regionsspezifische segmentierungsmutanten bei Drosophila melanogaster meigen. Ph.D. thesis, Univ. Tübingen.

Lehner, C. F. and O'Farrell, P. H. (1990). The roles of Drosophila cyclins A and $B$ in mitotic control. Cell $\mathbf{6 1}, 535-547$.

Lindsley D. L. and Zimm, G. (1992). The Genome of Drosophila melanogaster. San Diego: Academic Press.

Lohnes, D., Kastner, P., Dierich, A., Mark, M., LeMeur, M. and Chambon, P. (1993). Function of retinoic acid receptor $\gamma$ in the mouse. Cell 673, 643658.

Lyttle, T. W. (1993). Cheaters sometimes prosper: distortion of Mendelian segregation by meiotic drive. Trends Genet. 9, 205-210.

McLean, J. R., Merrill, C. J., Powers, P. A. and Ganetzky, B. (1994). Functional identification of the Segregation distorter locus of Drosophila melanogaster by germline transformation. Genetics 137, 201-209.

McMahon, A. P. and Bradley, A. (1990). The Wnt-1 (int-1) proto-oncogene is required for development of a large region of the mouse brain. Cell 62, 10731085 ;

Nauber, U., Pankratz, M. J., Kienlin, A., Seifert, E., Klemm, U. and Jäckle, H. (1988). Abdominal segmentation of the Drosophila embryo requires a hormone receptor-like protein encoded by the gap gene knirps. Nature 336, 489-492.

Nüsslein-Volhard, C. (1977). Genetic analysis of pattern formation in the embryo of Drosophila melanogaster. Roux's Arch. Dev. Biol. 183, 249-268.

Nurse, P. (1990). Universal control mechanism regulating onset of M-phase. Nature 344, 503-508.

O'Farrell, P. H. (1992). Big genes and little genes and deadlines for transcription. Nature 359, 366-367.

Pankratz, M. J. and Jäckle, H. (1993). Blastoderm Segmentation. In The Development of Drosophila melanogaster. (ed. M. Bate and A. Martinez-
Arias). Cold Spring Harbor, New York: Cold Spring Harbor Laboratory Press.

Philp, A. V., Axton, J. M., Saunders, R. D. C. and Glover, D. M. (1993). Mutations in the Drosophila melanogaster three rows permit aspects of mitosis to continue in the absence of chromatid segregation. J. Cell Sci. 106, 87-98.

Robertson, H. M., Preston, C. R., Phillis, R. W., Johnson-Schlitz, D. M., Benz, W. K. and Engels, W. R. (1988). A stable genomic source of P element transposase in Drosophila melanogaster. Genetics 118, 461-470.

Rattner, J. B., Kingwell, B. G. and Fritzler, M. J. (1988). Detection of distinct structural domains within the primary constriction using autoantibodies. Chromosoma 96, 360-367.

Rothe, M., Nauber, U., and Jäckle, H. (1989). Three identical receptor-like Drosophila genes encode an identical DNA-binding finger. EMBO J. 8, 3087 -3094 .

Rothe, M., Pehl, M., Taubert, H. and Jäckle, H. (1992). Loss of gene function through rapid mitotic cycles in the Drosophila embryo. Nature 359, $156-159$.

Rothe, M., Wimmer, E. A., Pankratz, M. J., González-Gaitán, M. and Jäckle, H. (1994). Identical transacting factor requirement for knirps and knirps-related gene expression in the anterior but not in the posterior region of the Drosophila embryo. Mech. Dev. 46, 169-181.

Sambrook, J., Fritsch, E. F. and Maniatis, T. (1989). Molecular Cloning: a Laboratory Manual. Cold Spring Harbor, New York: Cold Spring Harbor Laboratory Press.

Shermoen, A. V. and O'Farrell, P. H. (1991). Progression of the cell cycle through mitosis leads to abortion of nascent transcripts. Nature 67, 303-310.

St Johnston, D. and C. Nüsslein-Volhard, C. (1992). The origin of pattern and polarity in the Drosophila embryo. Cell 68, 201-219.

Sullivan, W., Minden, J. S. and Alberts, B. M. (1990). daughterless-abo-like, a Drosophila maternal-effect mutation that exhibits abnormal centrosome separation during the late blastoderm divisions. Development 110, 311-323.

Swaffield, J. C., Bromberg, J. F. and Johnston, S. A. (1992). Alterations in a yeast protein resembling HIV Tat-binding protein relieve requirement for an acidic activation domain in GAL4. Nature 357, 698-700.

Theurkauf, W. E., Alberts, B. M., Jan, Y. N. and Jongens, T. A. (1993). A central role for microtubuoles in the differentiation of Drosophila oocytes. Development 118, 1169-1180.

Thomas, K. R. and Capecchi, M. R. (1990). Targeted disruption of the murine int-1 proto-oncogene resulting in severe abnormalities in midbrain and cerebellar development. Nature 346, 847-850.

Thomas, J. H. (1993). Thinking about genetic redundancy. Trends Genet. 9 , 395-399.

Thummel, C. S., Burtis, K. C. and Hogness, D. S. (1990). Spatial and temporal patterns of E74 transcription during Drosophila development. Cell 61, 101-111.

Wharton, R. and Struhl, G. (1989). Structure of the Drosophila Bicaudal D protein and its role in localizing the posterior determinant nanos. Cell 59, 881-892. 